\title{
Neighborhood structure and the evolution of cooperation
}

\author{
Tackseung Jun • Rajiv Sethi
}

Published online: 28 November 2007

(C) Springer-Verlag 2007

\section{Erratum to: JEE (2007) 17:623-646 \\ DOI 10.1007/s00191-007-0064-6}

Unfortunately, the acknowledgement for financial support was missing in the original paper. Please note as follows:

The research of the article Neighborhood structure and the evolution of cooperation by Tackseung Jun and Rajiv Sethi was supported by the Kyung Hee University Research Fund in 2003 (KHU - 20030865).

The online version of the original article can be found at http://dx.doi.org/10.1007/s00191-007-0064-6.

T. Jun

Department of Economics, Kyung Hee University, 1 Hoegi-dong, Dongdaemoon-gu, Seoul 130-701, South Korea

e-mail: tj32k@daum.net

R. Sethi $(\bowtie)$

Department of Economics, Barnard College, Columbia University, 3009 Broadway, New York, NY 10027, USA

e-mail: rs328@columbia.edu 